\title{
PAKISTANI MEDIA AND THE RISING FEAR OF DENGUE FEVER.
}

1. MBBS, FCPS

Associate Professor

Medical Unit-II Civil Hospital

Dow University Health Sciences Karachi.

2. MBBS, FCPS

Assistant Professor

Medical Unit-II Civil Hospital

Dow University Health Sciences Karachi.

3. MBBS, FCPS

Assistant Professor

Medical Unit-II Civil Hospital

Dow University Health Sciences

Karachi.

Correspondence Address:

Dr. Darshan Kumar

Medical Unit-II Civil Hospital

Dow University Health Sciences

Karachi.

darshankumardow@gmail.com

Article received on:

$12 / 11 / 2019$

Accepted for publication:

$15 / 01 / 2020$

\begin{abstract}
Darshan Kumar ${ }^{1}$, Majid Ahmed Shaikh ${ }^{2}$, Syed Muhammad Kashif ${ }^{3}$
\end{abstract}
\begin{abstract}
Objectives: In this study we analyze how much the general population fear from dengue fever based on their knowledge acquired via media. Study Design: Cross-sectional study. Setting: Civil Hospital, Karachi, Pakistan. Period: $1^{\text {st }}$ August 2019 to $30^{\text {th }}$ September 2019. Material \& Method: Non-Probability consecutive sample technique was used. Patients with dengue fever were asked to fill a questionnaire which comprised of demographic variables as well as questions regarding their fear of dengue fever based on their information acquired from media particularly news channels. Results: Out of 2750 patients who underwent dengue serology, 727 came positive for active dengue viral infection. Of them 204 patients required admission. Patients were asked to rate how much they think dengue fever is lethal. The mean of all responses was $7.8(p<0.005)$. When asked about the route of transmission $93 \%$ answered the correct mode of transmission. 59.4\% $(n=432)$ think that dengue fever requires anti-biotics while $40.5 \%(n=295)$ knew that the management of dengue fever is supportive. We asked the study subjects about what did they know about dengue hemmorhagic fever and dengue shock. Of the 727 individuals, $10.3 \%(n=75)$ knew regarding any of them. $89.6 \%$ had no idea. Conclusion: We hereby conclude that although media has done a great job in educating the people, it has also created a fear among the general population regarding dengue fever which the clinicians face every day.
\end{abstract}

Key words: Dengue fever, Media, Rising Fear.

Article Citation: Kumar D, Shaikh MA, Kashif SM. Pakistani media and the rising fear of dengue fever. Professional Med J 2020; 27(4):853-856.

DOI: 10.29309/TPMJ/2020.27.04.4335

\section{INTRODUCTION}

Dengue fever is a viral infection transmitted by the Aedes Aegypti mosquito. In 2011, 21,204 cases were reported in Pakistan. ${ }^{1}$ Uptil now, a total of 50,000 patients in Pakistan have been diagnosed with dengue fever. ${ }^{2}$ There is no vaccine to prevent dengue fever is available, and effective prevention measures to control the spread include reducing breeding sites of aedes mosquito. Storage of water in open spaces leads to breeding to mosquito and spread of virus. ${ }^{3}$ Media plays a critical role in the prevention of dengue virus infection. ${ }^{4}$ Though its role in educating people regarding its prevention cannot be under-estimated, it is seen that media has also created a fear amongst the population regarding dengue fever. In this study we analyze how much the general population fear from dengue fever based on their knowledge acquired via media.

\section{MATERIALS AND METHOD}

This cross-sectional study was conducted in Civil Hospital, Karachi, Pakistan during the duration starting from $1^{\text {st }}$ August 2019 to $30^{\text {th }}$ September 2019.

Patients presenting to the outpatient department on every Thursday were included in the study. A total of 2750 patients presented with high grade fever, chills, body ache and headache. Of them 727 patients had positive dengue serology. These patients were included in the study. Informed consent was taken before including them in the study. Demographic variables were recorded which included age, gender, weight, height. All of them underwent baseline investigations including complete blood picture (CBC), Serum Urea, Serum Creatinine, Serum Electrolytes, Urine detailed report. They also underwent Serology testing for dengue virus-specific antibodies, 
types IgG and IgM. Investigations were available 12 hours later and supportive treatment was started irrespective of the laboratory reports. Patients were asked to fill a questionnaire which was comprised of questions related to the role of media in the awareness regarding dengue fever. After filling the questionnaire they were educated about the answers and asked to spread the awareness regarding it.

\section{RESULTS}

Out of 2750 patients who underwent dengue serology, 727 came positive for active dengue viral infection. Of them 424 were males and 303 were females. Of the 727 with positive dengue serology, 204 patients required admission. Of them 154 had symptoms for the last three days, 32 had symptoms for more than three days but less than seven days, 8 patients had symptoms for greater than 7 days (Table-I). Patients were asked if they regularly watch news regarding dengue fever $75 \%(n=546)$ responded yes (Figure-1). They further concluded that there are a lot of news regarding death related to dengue fever which creates panic among those diagnosed. When asked about the route of transmission 676(93\%) answered the correct mode of transmission which is by mosquito bite and can be prevented by limiting the breeding sites of Aedes mosquito (Figure-2). They were further asked if dengue fever is a viral disease of bacterial disease. $67 \%$ $(n=488)$ said that dengue fever is viral disease whereas $32.8 \%(n=239)$ said that dengue fever is bacterial (Table-II). They were further asked if the treatment of dengue fever involves the use of anti-biotics or just the use of anti-pyretics, analgesics and fluids. $59.4 \%(n=432)$ think that dengue fever requires anti-biotics while $40.5 \%$ $(n=295)$ knew that the management of dengue fever is supportive. When asked about the role of hydration in dengue fever, $71.8 \%(n=522)$ knew that hydration is important for the management of dengue while $28.1 \%(n=205)$ was unaware of the role of hydration in dengue fever. They were asked if any vaccine is available for the prevention of dengue fever. $51.7 \% \quad(n=376)$ conclude that vaccine is available whereas $48.2 \%$ $(n=351)$ conclude that there is no vaccine for the prevention of dengue fever. We asked the study subjects about what did they know about dengue hemmorhagic fever and dengue shock. Of the 727 individuals, $10.3 \%(n=75)$ knew regarding any of them. $89.6 \%(n=652)$ had no idea. Of the 50 who knew majority belonged to health care or have some first degree relatives in health care. Media hasn't contributed to the awareness of complications of dengue fever.

Patients were asked to rate how much they think dengue fever is lethal. The mean of all responses was $7.8(p=0.002)$. On the completion of questionnaire, we educated the individuals regarding dengue fever, its prevention, management and complications. We asked them to further spread this knowledge.

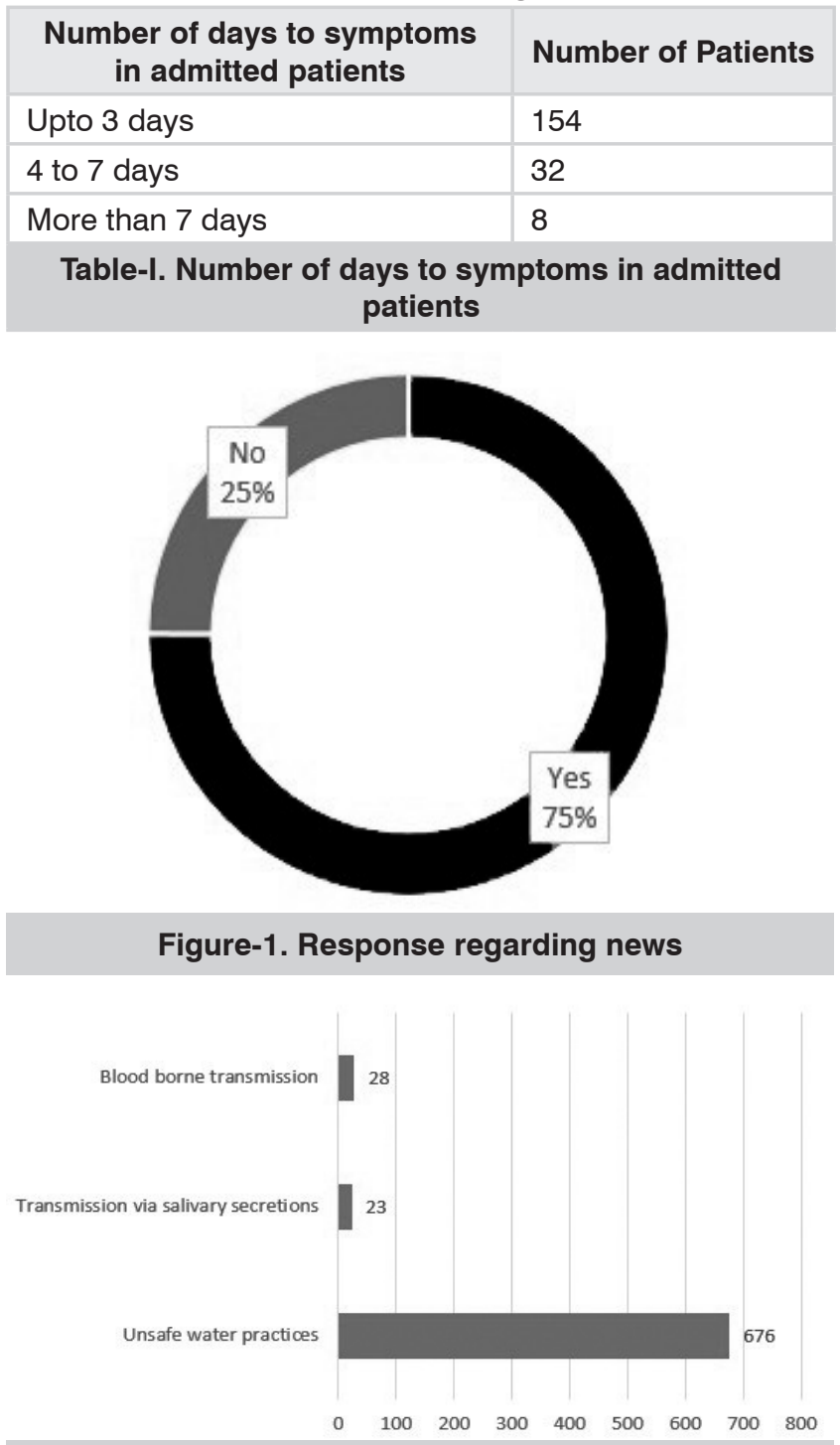

Figure-2. Response against the mode of transmission 
No. of Patients Percentage

Is dengue fever a viral disease or bacterial disease?

\begin{tabular}{|c|c|c|}
\hline Viral disease & 488 & $67.2 \%$ \\
\hline Bacterial disease & 239 & $32.8 \%$ \\
\hline \multicolumn{3}{|c|}{$\begin{array}{c}\text { Do you think hydration is important in the } \\
\text { management of dengue fever? }\end{array}$} \\
\hline Yes & 522 & $71.8 \%$ \\
\hline No & 205 & $28.1 \%$ \\
\hline Do you any vaccine is available to prevent dengue \\
fever?
\end{tabular}

\section{DISCUSSION}

Our study concludes that although media has contributed a lot to the awareness and prevention of dengue fever. It has also contributed to the development of fear against dengue fever. Dengue fever is curable with supportive management however the lay man's knowledge is solely based on the information he gained from media and thus fears dengue fever.

A study conducted in India shows that television is the most important source of information on dengue fever in majority of his study subjects. ${ }^{3}$ So the role of media is crucial most in the awareness of outbreaks of viral infections such as dengue fever. $32.8 \%$ of our patients think that dengue is a bacterial disease. We think that for the purpose of ratings, media has lost focus on the appropriate awareness of general population. Media focuses on reporting the incidence and death related to dengue fever. When we asked our study subjects how much you think dengue fever is lethal and asked them to rate their fear on a scale of 0 to 10 we found that the mean of all responses we received was 7.8 .

Though media has developed a fear among the general population for dengue fever. It has also helped in providing some awareness. Such as awareness regarding the prevention of dengue transmission. 93\% answered the correct mode of transmission of dengue fever which concludes that the media has provided appropriate awareness on the mode of transmission of dengue and its awareness. However it is concluded that media should pay more attention towards its transmission and management without creating a fear by continuously showing the death toll. A study conducted in Rawalpindi concludes that only $12 \%$ of his study subjects use mosquito nets to prevent dengue fever. ${ }^{5}$ Mosquito nets can only be used while sleeping however dengue virus transmission is possible during the day by mosquito bite which can be prevented by the use of mosquito repellants.

The potentially lethal complication of dengue fever is dengue hemmorhagic fever. Only $10.3 \%$ of population is aware of this complication. It involves hypovolemia, impairment of clotting mechanisms and increased vascular permeability. It can also lead to dengue shock. ${ }^{6}$ Media should clarify that the death due to dengue virus is particularly due to dengue hemmorhagic fever or dengue shock. Socio-economic status has a great correlation with the knowledge of prevention of dengue fever in previous studies. ${ }^{7}$ However in our study no association was found between socio-economic status and the fear of dengue virus.

One important step in the management of dengue fever, after subsiding the fever is hydration. It can be oral or intravenous. ${ }^{8}$ Of our study subjects, $26.2 \%$ were aware that hydration is an important step in the management of dengue fever. Of our study subjects, $63.6 \%$ patients believed that platelet transfusion is crucial in all forms of dengue fever. Media should focus on the awareness of fact the empirical transfusion of platelets is limited to patients with a platelet count less than 20,000-25,000 per $\mathrm{mm}^{3}$ and not every individual is a candidate for transfusion. The threshold for transfusion in any other febrile thrombocytopenia is less than 10,000 platelets per $\mathrm{mm}^{3} .^{9}$

The limitations of this study includes the relatively small sample size and the selection of patients tested positive for dengue fever. For the patients with negative dengue serology, the views might 
be different and further studies are required to discuss these facts.

\section{CONCLUSION}

We hereby conclude that although media has done a great job in educating the people, it has also created a fear among the general population regarding dengue fever which the clinicians face every day. Appropriate awareness without fear is the right of every citizen.

\section{Copyright(C) 15 Jan, 2020.}

\section{REFERENCES}

1. Khan E, Hasan R. Dengue infection in Asia; A regional concern. J Postgrad Med. 2011; 26:1-6.

2. Geo.tv. (2019). 50,000 tested positive for dengue across Pakistan, 250 dead, claim health officials. [online] Available at: https://www.geo.tv/latest/250956number-of-patients-tested-positive-for-dengue-virusacross-country-crosses-50000 [Accessed 24 Oct. 2019].

3. Arora $P$, Arora $M$, Sharma $V$, Kotwal A. Dengue: Awareness, preventive practices and water storage behaviour in an urban community of Delhi. International Journal of Community Medicine and Public Health. 2017 Nov 23; 4(12):4460-5.
4. Doblecki-Lewis S, Chang A, Jiddou-Yaldoo R, Tomashek KM, Stanek D, Anil L, Lichtenberger P. Knowledge, attitudes, and practices of Florida physicians regarding dengue before and after an educational intervention. BMC medical education. 2016 Dec; 16(1):124.

5. Siddiqui FR, Usmani AQ, Atif I, Hassan SBUS, Haider $\mathrm{SH}$. Are we aware of dengue fever? A community based KAP survey on dengue fever in Rawalpindi. J Islamic Int Med Coll. 2013; 8(3):69- 73.

6. WHO. Dengue and severe dengue. Fact Sheet No. 117, World Health Organization, Geneva, Switzerland. 2015. Available at 2015.

7. Itrat A, Khan A, Javaid S, Kamal M, Khan H, Javed S, et al. Knowledge, awareness and practices regarding dengue fever among the adult population of dengue hit cosmopolitan. PloS One. 2008; 3(7):e2620.

8. Harris E, Perez L, Phares CR, Perez Mde L, Idiaquez W, Rocha J, et al. Fluid intake and decreased risk for hospitalization for dengue fever, Nicaragua. Emerg Infect Dis 2003; 9:1003-6.

9. Dzieczkowski JS, Anderson KC. Transfusion biology and therapy. In: Braunwald E, Fauci AS, Kasper DL, Hauser SL, Longo DL, Jameson JL, editors. Harrison's Principle of Edition-15th Edition. New York: McGraw-Hill 2001: 733-38.

\begin{tabular}{|c|c|c|}
\hline \multicolumn{3}{|c}{ AUTHORSHIP AND CONTRIBUTION DECLARATION } \\
\hline Sr. \# & Author(s) Full Name & \multicolumn{1}{|c|}{ Contribution to the paper } \\
\hline 1 & Darshan Kumar & $\begin{array}{l}\text { Conception and design, } \\
\text { Statistical expertise, Critical } \\
\text { revision of the article for } \\
\text { important intellectual content } \\
\text { Data collection, Critical revision } \\
\text { of the article for important } \\
\text { intellectual content. } \\
\text { Drafting of the article. }\end{array}$ \\
\hline 2 & Majid Ahmed Shaikh & Syed M. Kashif
\end{tabular}

